\title{
Menos sorpresas e incertidumbre: propuesta de reforma a la Ley de Arbitraje y Mediación (LAM) en materia de responsabilidad civil de los árbitros, los centros de arbitraje y sus directores
}

\author{
Brisney David Molina Coello*
}

Recibido/Received: 26/07/2020

Aceptado/Accepted: 29/09/2020

\begin{abstract}
Sumario: 1. Introducción. 2. El panorama actual de la responsabilidad civil de los tribunales arbitrales, los centros de arbitraje y sus directores. 3. Consideraciones para una posible reforma a la LAM que prevea un régimen de responsabilidad civil para los árbitros, centros de arbitraje y sus directores. 3.1. Aceptación de la tesis mixta sobre la naturaleza del arbitraje. 3.2. Tipificación de los deberes de los árbitros, centros de arbitraje y sus directores. 3.3. Graduación de la culpa y otros requisitos para la imputación de responsabilidad. 4. Propuesta de reforma a la LAM. 5. Conclusiones.
\end{abstract}

Resumen: La LAM prevé responsabilidad civil para los árbitros, centros de arbitraje y sus directores. Sin embargo, no la regula con un régimen especial. Con posiciones divididas, la doctrina ecuatoriana afirma que el régimen civil o las normas

\footnotetext{
Asociado en Jaramillo Dávila Abogados. Entrenador del equipo de arbitraje y Profesor Adjunto de las clases de Arbitraje y Sucesiones en la Universidad de los Hemisferios (Ecuador). Embajador de Arbitrator Intelligence para el período 2020-2021. Colaborador para la creación y actualización de la Base de Datos de Arbitraje del Instituto Ecuatoriano de Arbitraje (Ecuador). Abogado Summa Cum Laude por la Universidad de los Hemisferios (Ecuador). Diplomado en Derecho de Daños por la Universidad Complutense de Madrid (España). Correo electrónico: dmolina@jaramillodavila.com

D. Molina Coello, "Menos sorpresas e incertidumbre: propuesta de reforma a la Ley de Arbitraje y Mediación (LAM) en materia de responsabilidad civil de los árbitros, los centros de arbitraje y sus directores", Revista Ecuatoriana de Arbitraje, No. 11, 2020, pp. 137-160.
} 
aplicables a los jueces podrían usarse alternativamente. Este trabajo propone un texto para una posible reforma a la LAM. Se recomienda que la ley: (i) adopte la teoría mixta sobre la naturaleza del arbitraje; (ii) tipifique los deberes de los árbitros y los directores; (iii) establezca reglas sobre la graduación de la culpa; e, (iv) incorpore requisitos especiales que acoplen la imputación de responsabilidad civil a la realidad del arbitraje.

Palabras Clave: responsabilidad civil, árbitros, directores, centros de arbitraje, reforma.

\section{Less surprises and uncertainty: proposal to reform the Arbitration and Mediation Law (LAM) in matters of civil liability of arbitrators, arbitration centers and their directors}

AвsтRACт: Ecuadorian Arbitration Law foresees civil liability for arbitrators, arbitration centers and directors. Nonetheless, it does not regulate it with a special regime. With divided positions, the Ecuadorian doctrine affirms that the contractual regime or the rules applicable to the judges could be used alternatively. This work proposes a text for a possible reform to the Ecuadorian Arbitration Law. It is recommended that it: (i) adopts the mixed theory on the nature of arbitration; (ii) typifies the duties of arbitrators and directors; (iii) establishes rules for the duty of care; and, (iv) incorporates special requirements that couple the imputation of civil liability to the reality of arbitration.

KeYwords: civil liability, arbitrators, directors, arbitration centers, law reform.

\section{INTRODUCCIÓN}

La posibilidad de que los tribunales arbitrales, los centros de arbitraje y sus directores sean responsables civilmente por 
las obligaciones que adquieren al sustanciar un proceso arbitral, ha sido aceptada sin mayor polémica en el Ecuador. La LAM prevé expresamente la responsabilidad de los árbitros, pero no la regula1․ También prevé deberes de los centros y sus directores, pero omite normar su responsabilidad. En este trabajo, se recogerán los pocos, pero valiosos desarrollos doctrinarios que se han realizado en el Ecuador sobre la responsabilidad de los tribunales arbitrales, delos centros de arbitraje administrado y de sus directores [2]. Luego, se expondrán ciertas consideraciones para plantear una reforma a la LAM en este ámbito y crear un régimen especial de responsabilidad civil, que se acople a la realidad del arbitraje [3]. Finalmente, se propondrá el texto para un posible cambio a dicho cuerpo normativo [4].

\section{El PANORAMA ACTUAL DE LA RESPONSABILIDAD CIVIL DE LOS TRIBUNALES ARBITRALES, LOS CENTROS DE ARBITRAJE Y SUS DIRECTORES}

En el Ecuador, los arbitrajes pueden ser ad hoc o administrados ${ }^{2}$. Los arbitrajes administrados son aquellos que utilizan las normas procedimentales de algún centro de arbitraje, donde también se suele sustanciar el proceso arbitral. Por su parte, los arbitrajes ad hoc se tramitan sin la necesidad de un centro de arbitraje, ante árbitros nombrados de manera independiente ${ }^{3}$. Esta distinción es importante para determinar a quiénes se les podría imputar responsabilidad civil.

En el arbitraje ad hoc, todos los actos del proceso arbitral son dictados por el tribunal arbitral, salvo su posesión, que se realiza ante un notario ${ }^{4}$. En el arbitraje administrado, el centro brinda servicios a las partes y su director sustancia ciertos

1. Ley de Arbitraje y Mediación, Artículo 18, RO No. 417, 14/12/2006, Última reforma en RO (S) No. 309, 21/08/2018.

2. Ídem, Artículo 2.

3. K. Herrera, "Aspectos actuales del arbitraje comercial internacional", Cuadernos de la maestría en Derecho, No. 6, 2017, pp. 272 y 273.

4. Ley de Arbitraje y Mediación, N. 1, Artículo 11. 
actos antes de la posesión del tribunal arbitral 5 . Es decir, si el arbitraje es ad hoc, la responsabilidad recaería sobre los árbitros, y sobre el notario únicamente por el acto de posesión; y, si es administrado, dependerá del acto que se busque imputar como incumplimiento, para que recaiga sobre el tribunal arbitral, el centro o su director.

A pesar de que no ha sido analizada doctrinariamente, la responsabilidad del notario está regulada expresamente en el artículo 44 de la Ley Notarial que manda: "[1]a infracción de los ordinales 3 y 4 del Art. 20 determina la nulidad de la escritura y el notario será destituido, sin perjuicio de las responsabilidades civiles o penales a que hubiere lugar" ${ }^{\prime \prime}$. Por lo que, si un laudo emitido en el marco de un arbitraje ad hoc es anulado por violación de ley en la posesión del tribunal arbitral', existiría responsabilidad del notario. Hecha esta precisión, se expondrán los aportes doctrinarios sobre la responsabilidad de los árbitros, los centros de arbitraje y sus directores que se han realizado en el Ecuador.

En primer lugar, el artículo 18 de la LAM prevé que los árbitros serán responsables en términos generales, por cualquier acción u omisión. Este manda:

[a]ceptado por los árbitros el cargo de tales, éstos tienen la obligación irrestricta de cumplir las funciones que la presente Ley les asigna, debiendo responder a las partes, en caso de incumplimiento de sus funciones por los daños y perjuicios que su acción u omisión les causare, a menos que se trate de un impedimento justificado [...] (énfasis añadido) ${ }^{8}$.

En otras palabras, la norma prevé que: (i) los árbitros deben cumplir las obligaciones que les asigna la ley; (ii) en caso de

5. Ídem, Artículos 10, 11, 15 y 17.

6. Ley Notarial contenida en el Decreto Supremo 1404, Artículo 44, RO No. 158, 11/11/1966, Última reforma en RO (S) No. 517, 26/06/2019.

7. Ley de Arbitraje y Mediación, N. 1, Artículo 31(e).

8. Ídem, Artículo 18. 
incumplimiento son responsables; (iii) por acción u omisión; (iv) salvo impedimento justificado. Sin embargo, dado que el artículo 7 del Código Orgánico de la Función Judicial (COFJ) prevé que "los árbitros ejercen potestades jurisdiccionales", lo que podría no ser claro es si el mencionado artículo de la LAM ratifica que los árbitros tienen la posición de jueces en el Ecuador, y responden como tales; o, si a pesar de tener potestades jurisdiccionales, responden como un contratista al que se le ha encargado hacer algo, en este caso: dirigir un proceso arbitral y emitir un laudo. De tomarse la primera tesis la responsabilidad civil sería de carácter extracontractual; y, con la segunda, sería de carácter contractual ${ }^{10}$.

Esta disyuntiva es especialmente importante al comparar los sistemas jurídicos anglosajón y de derecho continental. En el common law se prevé que los árbitros son semejantes a los jueces y tienen inmunidad en la mayoría de los casos, por lo que son responsables en escenarios limitados ${ }^{11}$. En el civil law se suele afirmar que los árbitros no son jueces, por lo que su responsabilidad se basa en el régimen general, y no se limita a escenarios en los que no tengan inmunidad ${ }^{12}$. En el caso ecuatoriano, los jueces no tienen inmunidad y son responsables por sus fallos ${ }^{13}$, y lo mismo pasa con los árbitros ${ }^{14}$, por lo que este dilema perdería utilidad práctica. Sin embargo, existen otros escenarios en los que es importante determinar si la responsabilidad civil de los árbitros y directores de centros de arbitraje es contractual o extracontractual. Es decir, si son o no semejantes a los jueces. Por ejemplo: (i) el plazo de

9. Código Orgánico de la Función Judicial, Artículo 7, RO (S) No. 544, 09/03/2009, Última reforma en Resolución No. 35 de la Corte Constitucional de Justicia, 30/06/2020.

10. J. JarAmillo, "La responsabilidad civil de los árbitros en el Ecuador: hacia la regulación de un ámbito no explorado", Revista Ecuatoriana de Arbitraje, No. 8, 2016, pp. 323-328.

11. S. MAYnard, "The Current State of Arbitrator Ethics and Party Recourse Against Grievances", Arbitration Law Review, Vol. 8, 2016, p. 208.

12. J. Jaramillo, N. 10, p. 332.

13. Constitución de la República del Ecuador, Artículo 11(9) RO No. 449, Última reforma en RO(S) No. $40,12 / 03 / 2020$.

14. Ley de Arbitraje y Mediación, N. 1, Artículo 18. 
prescripción de la acción y (ii) la graduación de la culpa, que se desarrollará en la siguiente sección.

El profesor JARAMILLO TROYA, en su artículo "La responsabilidad civil de los árbitros en el Ecuador: hacia la regulación de un ámbito no explorado", publicado en la Revista Ecuatoriana de Arbitraje No. 8, afirmó que la responsabilidad de los árbitros es de carácter contractual y que estos no pueden ser asemejados a los jueces. Expresamente dice:

[...] a diferencia de los jueces los árbitros no tienen la facultad intrínseca de imperium para mediante el uso de la fuerza ejecutar sus decisiones, $y,[\ldots]$ los jueces no reciben un estipendio como honorario profesional por la prestación del servicio en cada caso específico pagado por las partes, ni pueden negociarlo ${ }^{15}$.

En relación a la responsabilidad del tribunal arbitral, afirma que a pesar de que los árbitros ejercen potestades jurisdiccionales con base en la ley, estas nacen de manera primigenia de la voluntad de las partes de designarles, a través de un contrato llamado receptum arbitri. Este, es un "contrato bilateral y atípico celebrado entre las partes litigiosas -como una sola parte- y el árbitro"16, que se perfecciona cuando este último acepta la designación de las partes para conformar el tribunal arbitral ${ }^{17}$, y que, en palabras del profesor JARAMILLO TROYA: "contiene una obligación de resultado por parte de los árbitros de proferir un laudo válido y ejecutable salvo en casos excepcionales en los que, por existir un "tribunal truncado", el cumplimiento de dicha obligación sea eximido"18.

El receptum arbitri tendrá las obligaciones nacidas tanto de la ley como de la cláusula arbitral suscrita entre las partes, con

15. J. JaRAmillo, N. 10, p. 332.

16. Ibídem, p. 324.

17. Ibídem, p. 326.

18. Ibídem, p. 325 . 
base en el efecto integrador de los $\operatorname{contratos}^{19}$, previsto en el artículo 1562 del Código Civil. Este manda: "[l]os contratos deben ejecutarse de buena fe, y por consiguiente obligan, no sólo a lo que en ellos se expresa, sino a todas las cosas que emanan precisamente de la naturaleza de la obligación, o que, por la ley o la costumbre, pertenecen a ella" ${ }^{20}$. Asimismo, el referido autor sostiene que los árbitros son responsables por culpa leve, conforme las reglas generales del Derecho Civil, por no existir norma especial al respecto ${ }^{21}$.

Por otro lado, cabe destacar que el profesor JARAMILLO TROYA ratifica que en el Ecuador no podría existir inmunidad de los árbitros, aun cuando las partes lo pacten en la cláusula arbitral, pues el Código Civil prohíbe la condonación del dolo futuro 22 . De forma directa, su artículo 1481 manda: “[...] La condonación del dolo futuro no vale" ${ }^{\prime 23}$.

Por las razones expuestas, afirma que la responsabilidad civil de los árbitros es de carácter contractual, con base en la teoría mixta sobre sus atribuciones. Pero, acepta que "el ordenamiento jurídico ecuatoriano no regula de manera expresa la responsabilidad de los árbitros por sus actos y omisiones durante el proceso arbitral" ${ }^{24}$; por lo que recomienda que esta "[...] sea expresamente regulada en un cuerpo normativo que establezca, de ser el caso, un estándar más estricto de culpabilidad y las particularidades aplicables a la relación jurídica entre los árbitros y las partes litigiosas" 25.

En apoyo a la tesis de la responsabilidad contractual de los árbitros, el profesor CORONEL JONES la incorporó en una

19. Ibídem, p. 326-328.

20. Codificación del Código Civil, RO (S) No. 46, 24/06/2005, Última reforma en RO(S) No. 96, 08/07/2019.

21. J. JaRAMillo, N. 10, p. 342.

22. Ibídem, p. 333.

23. Codificación del Código Civil, N. 20, Artículo 1481.

24. J. JaRAMILLO, N. 10, p. 338.

25. Ibídem, p. 345. 
propuesta de nueva ley de arbitraje, que fue publicada en su trabajo titulado: "Presente y Futuro del Arbitraje Comercial en el Ecuador: Hacia una nueva ley", en la Revista Ecuatoriana de Arbitraje No. 2. Su artículo 32 dice: "[...] RESPONSABILIDAD. - La aceptación obliga a los árbitros y, en su caso, a la institución arbitral, a cumplir el encargo, incurriendo si no lo hicieren, en responsabilidad por los daños y perjuicios que causaren por dolo o culpa inexcusable" ${ }^{26}$.

En el aporte del profesor CORONEL JONES: (i) se ratificó que, como actualmente manda el artículo 18 de la LAM, los árbitros tienen responsabilidad por el incumplimiento de su encargo; (ii) se incluyó en la norma a los centros de arbitraje; y, (iii) se aumentó la graduación de la culpa, para que la responsabilidad sea imputable únicamente por dolo o culpa grave. Esta propuesta, aunque ilustrativa, no se discute en la Asamblea Nacional como una posible reforma a la LAM.

En segundo lugar, el aporte en materia de responsabilidad de los centros de arbitraje administrado y de sus directores fue realizado por ORDÓÑEZ RiverA, en su artículo titulado: "Responsabilidad de los centros de arbitraje en Ecuador", que fue publicado en la Revista Ecuatoriana de Arbitraje No. 927. En este, prevé tratamientos distintos para la responsabilidad del centro de arbitraje administrado, que sería contractual, y para la de su director, que sería extracontractual.

Respecto a la responsabilidad del centro de arbitraje, afirma que esta nace de un contrato llamado de "Administración de Arbitraje" ${ }^{28}$. En este, el consentimiento se perfecciona por la oferta pública del centro de administrar el arbitraje; y, la aceptación de los suscriptores del convenio arbitral, cuando se

26. C. Coronel Jones, "Presente y Futuro del Arbitraje Comercial en el Ecuador: Hacia una nueva ley", Revista Ecuatoriana de Arbitraje, No. 2, 2010, p. 417.

27. N. ORdóÑEz, "Responsabilidad de los centros de arbitraje en el Ecuador", Revista Ecuatoriana de Arbitraje, No. 9, 2018, pp. 323-345.

28. Ibídem, p. 324. 
presenta la demanda ${ }^{29}$. Lo define como un contrato bilateral: "en virtud del cual dos o más partes se obligan a acudir a determinada institución arbitral para la administración de su arbitraje" $\mathrm{e}^{\prime 30}$, y esta a su vez se obliga a administrarlo, a cambio del pago de un precio $^{31}$. En consecuencia, el incumplimiento a las obligaciones del centro sería imputado con base en las normas generales de la responsabilidad contractual.

Así como el profesor Jaramillo Troya con el receptum arbitri, ORDÓÑEz RIVERA afirma que las cláusulas de exclusión de responsabilidad que tenga el centro en su reglamento, que forma parte de la oferta pública de administrar el arbitraje, no incluyen al dolo ni a la culpa grave, por la prohibición legal de condonar el dolo futuro ${ }^{32}$. Lo que sí permiten es la indemnidad por el hecho de terceros en el proceso arbitral, sean estos árbitros, mediadores, secretarios, peritos, entre otros; como sucede con los reglamentos del Centro de Arbitraje y Conciliación de la Cámara de Comercio de Guayaquil, el Centro de Arbitraje y Mediación de la Cámara de Comercio Ecuatoriano Americana, y el Centro de Arbitraje y Mediación de la Cámara de Comercio de Quito ${ }^{33}$.

Respecto a la responsabilidad del director del centro, dice que sus actuaciones tienen el carácter de jurisdiccionales, por lo que son imputables bajo el régimen de responsabilidad extracontractual, apoyando la teoría de que los árbitros y directores de los centros son homologables en facultades a los jueces en la justicia ordinaria. En otras palabras, su postura es que el "arbitraje está siendo asimilado a la administración de justicia que realiza la Función Judicial" ${ }^{34}$, pues el COFJ lo califica en su artículo 17 como un servicio público ${ }^{35}$.

29. Ibídem, p. 327.

30. Ibídem, p. 325.

31. Ibídem, p. 328 y 329.

32. Ibídem, p. 332.

33. Ibídem, p. 330 y 331 .

34. Ibídem, p. 333.

35. Código Orgánico de la Función Judicial, N. 9, Artículo 17. 
La autora afirma que los actos imputables al director del centro son: "la calificación de la demanda, la citación, la resolución de la recusación y las notificaciones de actuaciones procesales durante la etapa pre arbitral" ${ }^{\prime 36}$. Estos son de carácter jurisdiccional por cuatro razones: (i) son actos que sustancia el tribunal arbitral en el arbitraje ad hoc; (ii) también son actos que normalmente realizan los jueces; (iii) tienen incidencia directa en el arbitraje; y, (iv) su ausencia o nulidad podrían anular el proceso arbitral, como sucede con la citación de la demanda ${ }^{37}$.

Así, la postura de ORDÓÑEz Rivera es que el director del centro, y aunque no lo dice se entendería que también los árbitros, tienen los mismos escenarios de responsabilidad que los jueces. Estos son: (i) retardo injustificado en sus actuaciones, (ii) negligencia, (iii) denegación de justicia y (iv) quebrantamiento de ley ${ }^{38}$.

En suma, existen posiciones contrarias respecto a cuál es la naturaleza de las funciones de los árbitros y de los directores de los centros de arbitraje en el Ecuador, lo que implica apreciaciones diferentes de cómo debería regularse su responsabilidad. De todos modos, lo que queda claro es que se podría imputar responsabilidad por incumplimientos en la sustanciación de un proceso arbitral a los árbitros, al notario únicamente por el acto de posesión del tribunal arbitral, al centro de arbitraje administrado y a su director.

36. N. OrdóÑEZ, N. 27, p. 338.

37. Ibídem, p. 336-338.

38. Ibídem, p. 341-344. 
3. CoNSIDERACIONES PARA UNA POSIBLE REFORMA A LA LAM QUE PREVEA UN RÉGIMEN DE RESPONSABILIDAD CIVIL PARA LOS ÁRBITROS, CENTROS DE ARBITRAJE Y SUS DIRECTORES

Antes de desarrollar las ideas que podrían recogerse en una reforma a la LAM en materia de responsabilidad de lo árbitros, centros de arbitraje y sus directores, cabe realizar una precisión. Lejos de volver el sistema más permisivo para los litigantes, y pernicioso para quienes resuelven y administran las controversias, lo que podría generar desincentivos para el crecimiento del arbitraje en el Ecuador, una posible reforma a la LAM permitirá unificar las posturas que se analizaron en la sección anterior y darles un alcance previsible. Es decir, fortalecer la seguridad jurídica.

Los árbitros ya son civilmente responsables por sus actuaciones, con base en el actual artículo 18 de la LAM. Lo mismo sucede con los centros, por el régimen general, y con los directores y notarios, por las normas sobre el ejercicio de la potestad jurisdiccional. Sin embargo, lo que es incierto es el alcance y la aplicación de dichas normas en el arbitraje, que tiene características propias.

Entonces, ¿qué utilidad tiene reformar la LAM para regular una responsabilidad que ya existe? La respuesta es eliminar la especulación sobre su alcance, con reglas claras sobre su aplicación y creadas con especial atención de las características propias del arbitraje.

Una posible reforma a la LAM debería abordar tres temas principales: la naturaleza de las atribuciones de los árbitros y de los directores de los centros de arbitraje administrado [3.1]; la tipificación de los deberes de los árbitros y directores en el marco de un proceso arbitral [3.2]; y, la graduación de la culpa en caso de incumplimiento y otros requisitos especiales 
que requiere el sistema arbitral para la imputación de responsabilidad civil [3.3].

\subsection{Aceptación de la tesis mixta sobre la naturaleza del arbitraje}

La naturaleza de las atribuciones de los árbitros y de los directores de los centros de arbitraje corresponderá a la teoría que se adopte. Existen cuatro. (i) La teoría jurisdiccional, en virtud de la cual los árbitros son equiparables a los jueces y su potestad nace de la ley. (ii) La teoría contractual, que afirma que el receptum arbitri es origen de las potestades del tribunal arbitral. (iii) La teoría ecléctica o mixta, que analiza la problemática en dos momentos: en el primero, acepta que la facultad primigenia de laudar nace en el receptum arbitri; $\mathrm{y}$, en el segundo, que empieza con la investidura de los árbitros, afirma que estos ejercen potestades jurisdiccionales conforme manda la ley. Y, (iv) la última teoría que rechaza las anteriores y afirma que la naturaleza del arbitraje es autónoma, por no corresponder ni por analogía a otra institución jurídica ${ }^{39}$.

Tanto la teoría jurisdiccional como la contractual no deberían implementarse en el Ecuador, pues abordan parcialmente el fenómeno del arbitraje. Afirmar que la razón principal por la que los árbitros son responsables es por que tienen potestades jurisdiccionales previstas legalmente, sería poner en segundo plano el papel de la autonomía de la voluntad de las partes, que es el principio más importante del sistema arbitral ${ }^{40}$. Por otro lado, afirmar que la razón más importante por la que los árbitros tienen la potestad de laudar es el pacto de los litigantes, sería minimizar la importancia del reconocimiento que se da al arbitraje en la Constitución,

39. F. GonzÁlez de Cossío, "Sobre la Naturaleza Jurídica del Arbitraje, Homenaje a Don Raúl Medina Mora", de Colección Foro de la Barra Mexicana, Themis, México D.F., 2008, pp. 14-16.

40. J. Graham, Lecciones de Arbitraje Internacional, Zamanga Editores, Monterrey, 2018, p. 505. 
como una excepción al principio de unidad jurisdiccional con regulación propia ${ }^{41}$. Quedan la teoría mixta y la autónoma.

Para regular la responsabilidad de los árbitros, directores y centros de arbitraje desde la teoría autónoma de la naturaleza del arbitraje, se necesitaría la creación de todo un régimen autocontenido. Ello debido a que, como se dijo, esta teoría afirma que el arbitraje es una institución que es única en el mundo jurídico. Por esta razón, una reforma realizada en esta línea debería ser extremadamente precisa y podría limitar sobremanera el sistema de responsabilidad que se proponga; o, por el contrario, extenderlo de forma muy general. En este sentido, no brindaría una solución ideal.

La teoría mixta sería la mejor opción. Al aceptar que la potestad de los árbitros y directores de los centros de arbitraje nace de la voluntad de las partes, plasmada tanto en el receptum arbitri como en el Contrato de Administración de Arbitraje, la LAM podría hacer una remisión expresa al régimen de responsabilidad civil contractual, que ya está regulado en el Código Civil. Asimismo, por la aceptación de la naturaleza jurisdiccional del arbitraje en un segundo momento, se podrían matizar las reglas de responsabilidad y ajustarlas a la realidad del sistema arbitral. Por lo tanto, una reforma a la LAM en materia de responsabilidad de los árbitros, centros de arbitraje y sus directores debería aceptar esta teoría e incorporar normas que la fortalezcan.

\subsection{Determinación de los deberes de los árbitros, centros de arbitraje y sus directores}

También, se deberían enumerar los deberes de los árbitros, en lugar de que exista una cláusula general de responsabilidad por cualquier acto u omisión, como sucede con el actual

41. Constitución de la República del Ecuador, N. 13, Artículo 190. 
artículo 18 de la LAM. Ello debido a que, como se dijo, a pesar de que el génesis del arbitraje es la voluntad de las partes, no se puede negar que este es una excepción al principio de unidad jurisdiccional y que los árbitros resuelven controversias en ejercicio de la potestad de juzgar. Por ello, a pesar de que el régimen de responsabilidad debería ser el contractual, este requiere matices propios, que limiten y determinen las consecuencias de los incumplimientos de los árbitros y los directores de los centros, diferenciando sus obligaciones eminentemente contractuales de aquellas que devienen del ejercicio de la potestad jurisdiccional. Esto también tomando en cuenta que, excluyendo al Ecuador, "para prevenir que la parte vencida hostigue a los árbitros, no hay un sistema legal que permita la responsabilidad por cualquier error o juicio que estos puedan cometer" ${ }^{42}$. La regulación es necesaria.

Los deberes de los árbitros en un proceso arbitral se pueden organizar en cuatro categorías: (i) conducir el proceso arbitral de forma justa, independiente e imparcial; (ii) cumplir los plazos legales o contractuales previstos para el ejercicio de sus funciones; (iii) mantenerse en funciones hasta la emisión del laudo, sin poder renunciar sin una razón válida luego de haber aceptado el encargo; $y$, (iv) el deber de confidencialidad ${ }^{43}$. El cumplimiento de los plazos contractuales y el deber de confidencialidad son ejemplos de obligaciones impuestas contractualmente, mientras que las demás se encasillan en obligaciones legales que el árbitro debe observar en el ejercicio de sus funciones.

Como ya se mencionó, los deberes de los directores del centro, en ejercicio de la potestad jurisdiccional, son: (i) calificar la demanda, (ii) realizar la citación, (iii) resolver la

42. Traducción libre. A. CEvc, "Civil Liability of Arbitrators", en D. Duć, EU and Comparative Law Issues Challenges Series (Ecic C): International Scientific Conference of EU and Member States Legal and Economic Issues, Facultad de Derecho, Josip Juraj Strossmayer de la Universidad de Osijek, 2019, p. 409.

43. Traducción libre. Ibídem, p. 413. 
recusación y (iv) notificar las actuaciones procesales en la etapa pre arbitral ${ }^{44}$.

En materia de responsabilidad de los centros de arbitraje no se requeriría realizar matices de sus responsabilidades ni tipificarlas, pues no ejercen potestades jurisdiccionales, pero una opción podría ser unificar su régimen de responsabilidad con el del director del centro, para que exista responsabilidad solidaria, toda vez que este es un funcionario de dicha institución.

\subsection{Graduación de la culpa y otros requisitos para la imputación de responsabilidad}

El efecto práctico de tipificar las responsabilidades de árbitros y directores sería la graduación de la culpa para adjudicarles responsabilidad, diferenciando cuáles de sus obligaciones son eminentemente contractuales y cuáles derivan del ejercicio de la potestad de juzgar. Ello para que el incumplimiento de las obligaciones que se ejecutan con la potestad jurisdiccional requiera un estándar más alto que las demás y, en consecuencia, sea más difícil declarar responsabilidad por su quebrantamiento.

Para que exista responsabilidad civil contractual deben cumplirse los siguientes requisitos: (i) la existencia de un contrato válido; (ii) el incumplimiento; (iii) la culpa o dolo del deudor; (iv) el daño; y, (v) el nexo causal ${ }^{45}$. La culpa es el elemento subjetivo de la responsabilidad civil y se refiere al descuido del deudor en el acto u omisión por el que se causa el incumplimiento. Esta tiene tres niveles: la culpa grave, leve y levísima; y, junto con el dolo, está regulada en el artículo 29 del Código Civil, que manda:

44. N. ORdóÑEZ, N. 27, p. 338.

45. L. Díez Picazo \& A. Gullón, Sistema de Derecho Civil, Vol. II, Editorial Tecnos, Madrid, 2012, p. 227. 
Culpa grave, [...] es la que consiste en no manejar los negocios ajenos con aquel cuidado que aún las personas negligentes y de poca prudencia suelen emplear en sus negocios propios. Esta culpa, en materias civiles, equivale al dolo.

Culpa leve, [...] es la falta de aquella diligencia y cuidado que los hombres emplean ordinariamente en sus negocios propios. Culpa o descuido, sin otra calificación, significa culpa o descuido leve. [...]

Culpa o descuido levísimo, es la falta de aquella esmerada diligencia que un hombre juicioso emplea en la administración de sus negocios importantes. [...]

El dolo consiste en la intención positiva de irrogar injuria a la persona o propiedad de otro ${ }^{46}$.

Cada nivel de culpa tiene un estándar probatorio distinto. La culpa levísima está implícita en el hecho del incumplimiento, por ser la falta de la esmerada diligencia. Por otro lado, la culpa leve requiere la prueba de un descuido medio. Finalmente, la culpa lata y el dolo demandan probar la intención del acreedor de causarle daño al deudor, o la ausencia de cualquier grado de diligencia en sus actuaciones.

Para el régimen de responsabilidad de árbitros y directores de los centros de arbitraje, lo razonable sería que se les impute responsabilidad únicamente por culpa grave o dolo, ante el incumplimiento de las obligaciones que implican el uso de sus potestades jurisdiccionales ${ }^{47}$. En esos casos, como sucede en el Derecho anglosajón ${ }^{48}$, el tribunal arbitral sería responsable, por ejemplo, por la nulidad de un laudo arbitral, si hubiera incumplido de manera dolosa o especialmente negligente su deber de emitir un laudo válido y ejecutable; mas no por cualquier omisión dentro del proceso arbitral que llegue a anular el laudo. Asimismo, los árbitros serían responsables por el daño causado a la parte vencida en el arbitraje, si el laudo hubiese sido emitido con fraude o colusión, a pesar

46. Codificación del Código Civil, N. 20, Artículo 29.

47. A. Cevc, N. 42, p. 417.

48. Ibídem, p. 411. 
de que en un escenario normal el tribunal arbitral no está obligado a laudar de cierta manera, pues el resultado de la controversia es incierto ${ }^{49}$. Este mismo estándar sería aplicable para los directores de los centros de arbitraje.

Por otro lado, para las obligaciones de los árbitros y directores que no impliquen el uso de sus potestades jurisdiccionales, el incumplimiento debería imputarse por culpa leve. Este tipo de obligaciones requieren la diligencia de un contratante medio, conforme a las reglas del régimen general, al no implicar el uso de una potestad pública. Por ejemplo, el deber de confidencialidad no requiere el revestimiento de la culpa grave. Caso contrario, los árbitros, el centro y su director solo serían responsables por incumplirlo, en caso de que exista dolo o abierta negligencia, a pesar de haber causado un daño. Lo razonable es que la negligencia común sea suficiente para demandar el incumplimiento de las obligaciones eminentemente contractuales.

Como un requisito especial, para que exista responsabilidad del tribunal arbitral por el incumplimiento de sus obligaciones de carácter jurisdiccional, primero se requeriría de una sentencia que declare que el laudo tiene la falencia que se le busca imputar a los árbitros como un incumplimiento. Ello debido a que, en caso de que el laudo se mantenga incólume, este tiene el efecto de sentencia ejecutoriada y cosa juzgada, por mandato del artículo 32 de la LAM, por lo que se presume válido, legítimo y de cumplimiento forzoso ${ }^{50}$. Es decir, se presume también que el tribunal arbitral cumplió sus obligaciones.

En este punto, existe un matiz respecto al incumplimiento del plazo legal que tiene el tribunal arbitral para dictar el laudo, que es de hasta trescientos días contados desde la audiencia

49. Ibídem, p. 414.

50. Ley de Arbitraje y Mediación, N. 1, Artículo 32. 
de sustanciación del arbitraje ${ }^{51}$, en la que este declara sobre su propia competencia ${ }^{52}$. El laudo emitido en este escenario, que se califica como extemporáneo ${ }^{53}$, no forma parte de las causales de nulidad del laudo arbitral, previstas en el artículo 31 de la $\mathrm{LAM}^{54}$, tal y como sucede de manera expresa en la legislación española ${ }^{55}$. La Sala de lo Civil y Penal del Tribunal Superior de Justicia de Madrid dijo en sentencia de 19 de julio de 2019 que su legislador "no solo contempla la posibilidad de pacto de prórroga, sino que excluye la nulidad del laudo si el plazo máximo fuere excedido" ${ }^{56}$. Por lo tanto, esta obligación de carácter jurisdiccional no afectaría la validez del laudo arbitral y no podría impugnarse por la vía de nulidad.

La impugnación por la vía constitucional requeriría un análisis de cada caso, pues la Corte Interamericana de Derechos Humanos ha aceptado que existen escenarios en los que la demora en el juzgamiento es una violación del debido proceso en sí misma. Sin embargo, la regla general es que esta no implica la violación del referido derecho ${ }^{57}$. Por lo mismo, se mantendría la presunción de que la obligación fue cumplida una vez emitido el laudo extemporáneo y no se podría imputar responsabilidad civil a los árbitros por la demora.

Para imputar responsabilidad civil al tribunal arbitral en este caso, se requeriría que las partes recusen a los árbitros luego de fenecido el plazo para emitir el laudo. Ello debido a que la recusación es el efecto previsto en el ordenamiento

51. Ídem, Artículo 25.

52. Ídem, Artículo 22.

53. E. CAmpo Villegas, "Prejudicialidad penal: a propósito del laudo del Tribunal Arbitral de Barcelona de 1 de junio de 2012", Anuario de Justicia Alternativa, No. 12, España, Bosch Editor, 2012, p. 80.

54. Ley de Arbitraje y Mediación, N. 1, Artículo 31.

55. Ley 60/2003 del Reino de España, Artículo 37(2), BOE-A-2003-23646, 23/12/2003, Última modificación en 06/10/2015.

56. Sala de lo Civil y Penal del Tribunal Superior de Justicia de Madrid, Juan Francisco Rodríguez c. María José Rodríguez Teijerio, Sentencia No. 27/2019, 19/07/2019.

57. Corte Interamericana de Derechos Humanos, Caso de las Masacres de Ituango c. Colombia, Sentencia en Serie C No. 148, 01/07/2006. 
jurídico ecuatoriano en caso de demora del tribunal en dictar su resolución.

El artículo 21 de la LAM manda que las causales de recusación de los árbitros son: "las previstas en el Código de Procedimiento Civil para los jueces" ${ }^{\text {58. }}$. A su vez, la disposición reformatoria primera del Código Orgánico General de Procesos (COGEP) ordena que "[e]n todas las disposiciones legales o reglamentarias vigentes, sustitúyase en lo que diga: [...] "Código de Procedimiento Civil" [...] por "Código Orgánico General de Procesos" 59 . En este sentido, para recusar a los árbitros se deben aplicar las normas del COGEP. Su artículo 22 prescribe: "[s]on causas de excusa o recusación de la o el juzgador: [...] 5. Retardar de manera injustificada el despacho de los asuntos sometidos a su competencia. Si se trata de la resolución, se estará a lo dispuesto en el Código Orgánico de la Función Judicial" ${ }^{60}$. En concordancia, el artículo 15 del COFJ prevé la responsabilidad de los jueces por retardo injustificado ${ }^{61} ; \mathrm{y}$, el numeral segundo del artículo 165 manda que el efecto de la aceptación de la recusación es la pérdida de competencia ${ }^{62}$. Aceptada la recusación del tribunal arbitral, se podría iniciar un reclamo por el daño que causó su demora.

Recusar a los árbitros es un derecho que tienen las partes. Su abstención de usarlo implicaría la condonación de la mora en el deber de emitir el laudo en el plazo previsto en la ley. Por lo mismo, y como se dijo, sin recusación no existiría incumplimiento a pesar de que el laudo sea extemporáneo.

Por otro lado, las obligaciones eminentemente contractuales de los árbitros, directores y centros de arbitraje

58. Ley de Arbitraje y Mediación, N.1, Artículo 21.

59. Código Orgánico General de Procesos, Disposición reformatoria primera, RO(S) No. 506, 22/05/2015, Última reforma en RO (S) No. 517, 26/06/2019.

60. Ídem, Artículo 22.

61. Código Orgánico de la Función Judicial, N. 9, Artículo 15.

62. Ídem, Artículo 165. 
podrán demandarse sin necesidad de que se impugne el laudo arbitral.

Al cambiar el régimen en esta lid, se deberían prohibir legalmente las cláusulas de indemnidad de los centros de arbitraje, pues, a pesar de que no pueden condonar el dolo futuro, si pudieran condonar la culpa leve. Es decir, todas las obligaciones eminentemente contractuales del centro de arbitraje y su director.

Por lo expuesto, una reforma a la LAM podría considerar la teoría mixta sobre la naturaleza de las facultades de los árbitros y de los directores de los centros de arbitraje. Sus deberes deberían clasificarse y tipificarse en el texto de la ley, para graduar con culpa grave el incumplimiento de las obligaciones jurisdiccionales y con culpa leve de las contractuales. Se debería contar con una sentencia favorable de impugnación del laudo arbitral como requisito previo al reclamo por el incumplimiento de una obligación jurisdiccional del tribunal o del director del centro. Para imputar responsabilidad por la demora en la emisión del laudo, los árbitros deberían ser previamente recusados. Se deberían prohibir las cláusulas de indemnidad; $y$, el centro y su director deberían ser solidariamente responsables.

\section{Propuesta de Reforma a la LAM}

Con base en lo expuesto, un posible texto de reforma al actual Art. 18 de la LAM sería:

Art. 18.- Aceptado por los árbitros el encargo como tales, se perfeccionará entre las partes y el tribunal arbitral un contrato llamado de dación y recepción de arbitraje.

La posesión de los árbitros se realizará con atención al referido contrato y, desde el acto de investidura, los árbitros 
ejercerán las potestades jurisdiccionales o de juzgamiento previstas en esta Ley.

Art. 18.1.- Los deberes de los árbitros se clasifican en contractuales, como mantener la confidencialidad del proceso arbitral, y jurisdiccionales, como conducir el proceso arbitral de forma justa, independiente e imparcial, cumpliendo los plazos previstos en la ley, y emitir un laudo válido y ejecutable.

Los árbitros serán responsables civilmente por el incumplimiento de sus obligaciones. Por las obligaciones contractuales responderán por culpa leve, mientras que por las obligaciones jurisdiccionales responderán por culpa grave o lata, en los términos previstos en el Código Civil.

Para demandar el incumplimiento de una obligación jurisdiccional, a más de los requisitos para imputar responsabilidad civil, se requerirá impugnación favorable del laudo arbitral, ya sea por la vía de la acción de nulidad prevista en esta Ley, o por los demás mecanismos que fueren aplicables.

Si el tribunal arbitral incumple el plazo legal para la emisión del laudo, el requisito para demandar las respectivas indemnizaciones es que los árbitros hayan sido recusados conforme manda el Art. 21 de esta Ley.

Por su parte, las obligaciones contractuales serán exigibles desde que el tribunal arbitral esté en mora, con base en las normas del régimen general.

Art. 18.2.- La relación entre las partes y centros de arbitraje y mediación y sus directores será contractual. Esta se perfeccionará con la presentación de la demanda arbitral ante la referida institución y se regirá bajo las normas generales de los actos o contratos. 
Presentada la demanda, el director del centro tendrá las siguientes obligaciones jurisdiccionales: calificar la demanda, realizar la citación, resolver la recusación y notificar las actuaciones procesales hasta la posesión del tribunal arbitral. Su incumplimiento acarreará responsabilidad en los términos previstos en esta Ley para las obligaciones jurisdiccionales de los árbitros.

En caso de incumplimiento de las obligaciones del director, el centro de arbitraje será solidariamente responsable.

El notario será responsable por el acto de posesión del tribunal arbitral en el arbitraje independiente, de la misma forma que los directores del centro de arbitraje administrado. Ello sin perjuicio de las normas especiales que le sean aplicables.

Art. 18.3.-Cualquier disposición que prevea la indemnidad de algún tipo a favor del centro de arbitraje administrado, su director o los árbitros, será nula e inejecutable. Sea que esta se encuentre en el reglamento del centro, la cláusula arbitral o en cualquier otro documento afín al proceso arbitral.

Quedan excluidas las cláusulas que prevean escenarios de responsabilidad por el hecho de un tercero.

Finalmente, una posibilidad que no se ha recogido en este trabajo, pero que podría merecer la atención del legislador en caso de reformar la LAM en materia de responsabilidad de los árbitros, centros de arbitraje y sus directores, es la de prever la obligación de contar con un seguro de responsabilidad civil para ejercer el encargo de árbitro o para el funcionamiento de los centros de arbitraje y mediación. De esta forma, se podría procurar la reparación civil con una división de infortunios que aumente un costo fijo a los arbitrajes, a cambio de la seguridad de que, en caso de declararse judicialmente la responsabilidad civil, las indemnizaciones estarán cubiertas. 


\section{Conclusiones}

El artículo 18 de la LAM prevé la responsabilidad de los árbitros por cualquier acto u omisión. Asimismo, otras de sus disposiciones imponen deberes a los centros de arbitraje y a los directores, por las cuales son responsables. Existe una posición dividida en la doctrina ecuatoriana de si el incumplimiento de los árbitros y los directores permite imputarles responsabilidad civil contractual o extracontractual. La tesis que apoya la imputación de responsabilidad civil contractual afirma que los árbitros no pueden ser asemejados a los jueces ordinarios; mientras que la que apoya a la responsabilidad extracontractual aboga por su semejanza. Esta contraposición es importante, pues el régimen aplicable cambia dependiendo de la teoría que se acepte.

No existe un régimen especial para la responsabilidad civil de los árbitros, los centros de arbitraje y sus directores, más allá de la aceptación legal de que se les puede imputar este tipo de responsabilidad. En este sentido, una reforma a la LAM es necesaria.

En primer lugar, se debería aceptar la tesis mixta sobra la naturaleza de las atribuciones de los árbitros y los directores del centro. De este modo, se terminaría el debate de si su responsabilidad es contractual o extracontractual, prefiriéndose la contractual. Esto sin negar que los árbitros y directores ejercen potestades jurisdiccionales y, por esta misma razón, requieren reglas especiales.

En segundo lugar, se deberían enlistar las obligaciones de los árbitros y directores. Las de los árbitros se clasifican en: (i) conducir el arbitraje de forma justa, independiente e imparcial; (ii) cumplir los plazos legales o contractuales; (iii) mantenerse en funciones hasta la emisión del laudo; y, (iv) guardar la confidencialidad. Las de los directores son: (i) calificar la demanda, (ii) realizar la 
citación, (iii) resolver la recusación y (iv) notificar las actuaciones procesales hasta la posesión del tribunal arbitral.

En tercer lugar, se deberían prever normas de graduación de la culpa, en las que se diferencien las obligaciones de carácter jurisdiccional del tribunal arbitral y los directores, de aquellas de carácter contractual. Para imputar responsabilidad por las obligaciones jurisdiccionales se debería probar culpa grave y para las contractuales se debería probar culpa leve.

Las obligaciones de carácter jurisdiccional deberían ser exigibles siempre que el laudo arbitral haya sido impugnado exitosamente ya sea por la vía de nulidad o por la constitucional. En el caso especial del incumplimiento del plazo legal para laudar, las partes podrían pretender indemnizaciones siempre y cuando hayan recusado al tribunal arbitral. El laudo extemporáneo será válido y condonará la mora del tribunal que no haya sido recusado.

Finalmente, se podría prever en la LAM que los árbitros y los centros de arbitraje requieran de un seguro de responsabilidad civil para ejercer sus actividades. 